\title{
Pathological features and prenatal diagnosis in the newly recognised limb/pelvis-hypoplasia/aplasia syndrome
}

\author{
A RAAS-ROTHSCHILD*, R M GOODMAN*, S MEYER $\dagger$,

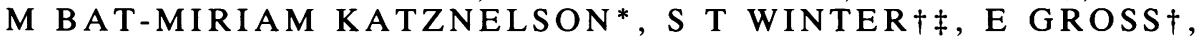 \\ M TAMARKIN, T BEN-AMI\|, L NEBELI, AND S MASHIACH \\ From the Departments of Medical Genetics*, Radiology\|, Embryology\|, and OB/GYN\$, Chaim Sheba \\ Medical Center, Tel-Hashomer, and the Sackler School of Medicine, Tel-Aviv University; the Alyn Hospital \\ and Hebrew University, Hadassah Medical School, Jerusalem; and łthe Technion University, Faculty of \\ Medicine, Haifa, Israel.
}

SUMmARY A second family with the autosomal recessive disorder now referred to as the $\mathrm{limb} /$ pelvis-hypoplasia/aplasia syndrome is reported. It is speculated that the gene for this rare skeletal dysplasia may be confined to the Middle East gene pool. The disorder has been shown to be diagnosable prenatally in a pregnancy at risk by using ultrasonography.

In 1985, Al-Awadi et al ${ }^{1}$ first briefly reported on two Arab sibs of consanguineous parents with a newly recognised skeletal dysplasia disorder, consisting of profound limb deficiency, thoracic dystrophy, unusual facies, and normal intelligence.

The purpose of this report is to describe and to discuss in detail a second affected consanguineous family with three affected offspring (the proband and the two aborted fetuses) with this disorder, which we now call the limb/pelvis-hypoplasia/aplasia syndrome. Our reasons for renaming this condition will be discussed.

\section{Case reports}

The proband (fig 1) was a $3.17 \mathrm{~kg}$ male, born by spontaneous vaginal delivery after an uneventful pregnancy. There was no history of teratogenic exposure or drug ingestion during the pregnancy. Serology for intrauterine infection was negative and a thrombocyte count of the baby was normal.

At birth (29 April 1982) the proband presented with severe upper and lower limb malformations. One month after birth, the parents and their affected child were referred to our genetic counselling clinic for evaluation. Physical examination at that time showed a male infant with markedly deformed extremities. The upper extremities showed severe shortening of the forearms. There were only

Received for publication 15 September 1987. Accepted for publication 8 October 1987. three abnormally shaped digits on each hand. The lower extremities showed severe phocomelic changes with absence of the feet. The external genitalia were displaced upwards. The penis appeared normal, but the scrotum was hypoplastic with bilateral cryptorchidism (fig 2). No other physical findings were noted. No definite diagnosis was made at that time but the parents were advised that, because of their consanguinity, they might be at risk for having similarly affected children. Furthermore, because of the severity of the malformations, it was suggested that all future pregnancies should be monitored by means of ultrasound, as there was a good chance

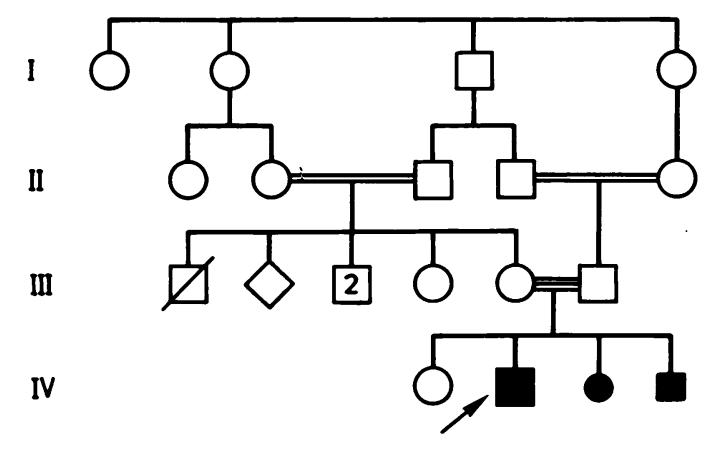

FIG 1 Pedigree showing the proband (arrow) and the two aborted fetuses. Note that the parents are double first cousins. 

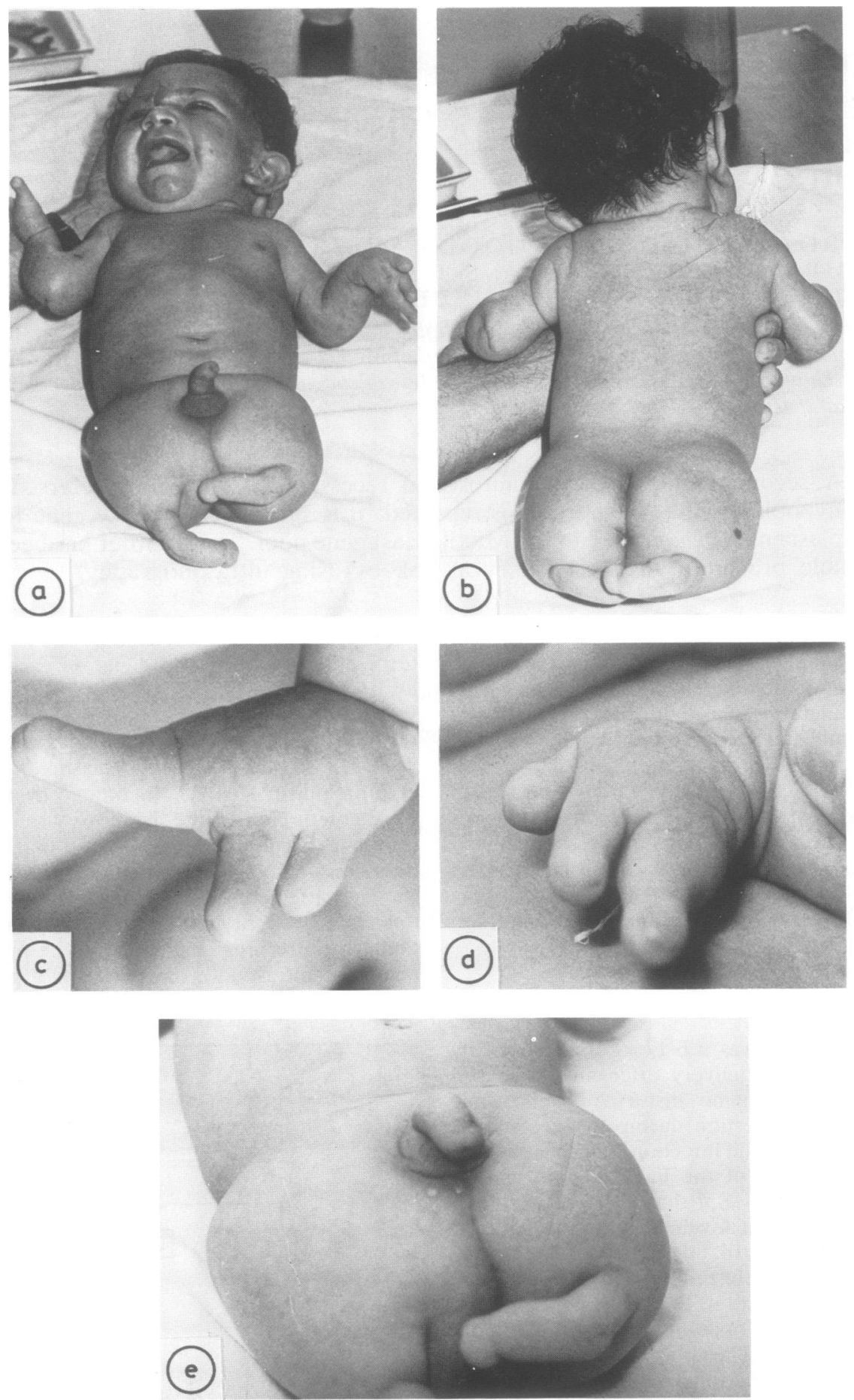

FIG 2 Proband aged one month, $(a, b)$ showing the severe malformations of upper and lower limbs; $(c, d)$ showing ectrodactyly and malformed digits; and (e) malformed pelvis with upward displacement of the external genitalia. 

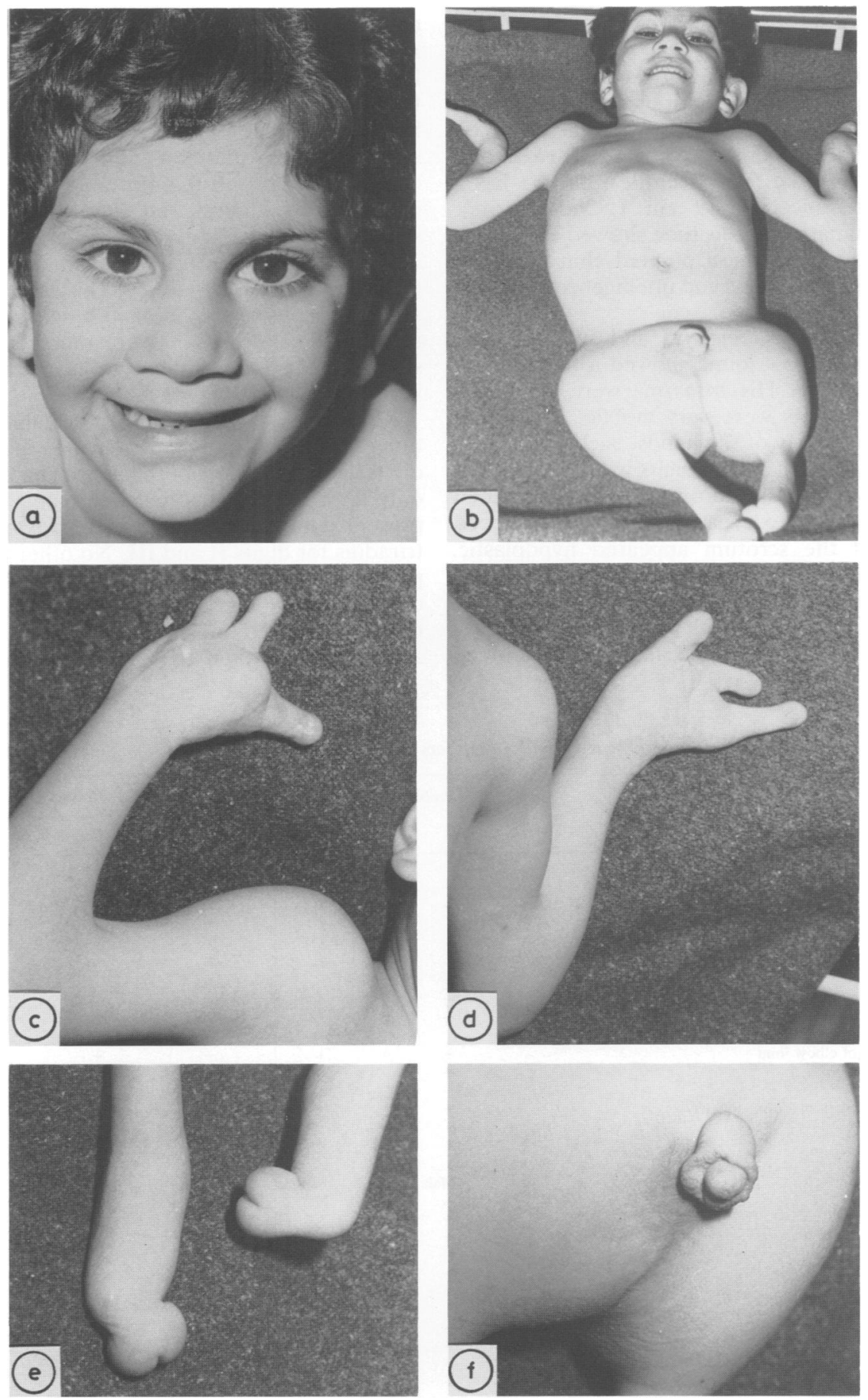

FIG 3 Proband aged four and a half years, (a) showing essentially normal facial features with a pointed chin; (b) severe limb malformations; $(c, d)$ ectrodactyly and malformed digits; (e) malformed lower limbs with appendages resembling hypoplastic feet; and $(f)$ upwardly displaced external genitalia with hypoplastic scrotum. 
that this disorder could be recognised early in pregnancy.

At approximately one year of age, the proband was placed in a hospital for crippled children (Alyn Hospital, Jerusalem) and this is where he currently resides. He is at present four and a half years old, his weight is $11.5 \mathrm{~kg}$ ( $<3 \mathrm{rd}$ centile), and he has a head circumference of $49 \mathrm{~cm}$ ( $>2$ nd centile). Physical examination at this time showed a boy with normal facies except for a pointed chin and long ears. His state of alertness and intelligence appeared to be normal for his age.

The upper limbs were short and symmetrically involved. Both elbow joints showed a flexion contracture deformity. His forearms were shortened and the wrist joints were very mobile. There was bilateral ectrodactyly of the hands, each having two fingers and a thumb, and all digits were malformed. The pelvis was grossly deformed. As commented upon previously, the external genitalia were displaced upwards and the scrotum appeared hypoplastic. Both testes were in the inguinal canal despite the fact that at three years of age he had had orchidopexy. $\mathrm{He}$ had no problems with urination or bowel continence. He had a pilonidal sinus which was deep and keratinised. There was a raised hairy pigmented naevus of $1.5 \mathrm{~cm}$ in diameter on the lateral side of his right thigh. There were only stick-like projections from the pelvic area, with appendages resembling hypoplastic feet. The key clinical findings are summarised in table 1 and the radiographical observations are listed in table 2. Figs 3 to 5 illustrate the clinical and radiographical features shown by the proband.

An abdominal ultrasound examination revealed the absence of a right kidney. This was confirmed by an intravenous pyelogram and renal scan. No other urogenital malformations were noted. Chromosomal studies showed the proband to have a normal male karyotype $(46, X Y)$.

Dermatoglyphic findings showed marked distortion of the digital and palmar prints, since only three digits were present on both hands. The left palm had only an axial triradius and one palmar crease was present. On the right palm there was one common triradius for digits II and III. No other triradii were present. On both palms there were many fine, small creases with no specific shape or direction. The left hand had a whorl on digit I, a radial loop on digit II, and an arch on digit III. The right hand had three

TABLE 1 Key clinical findings in our affected family members compared with those cases reported by Al-Awadi et al. ${ }^{1}$

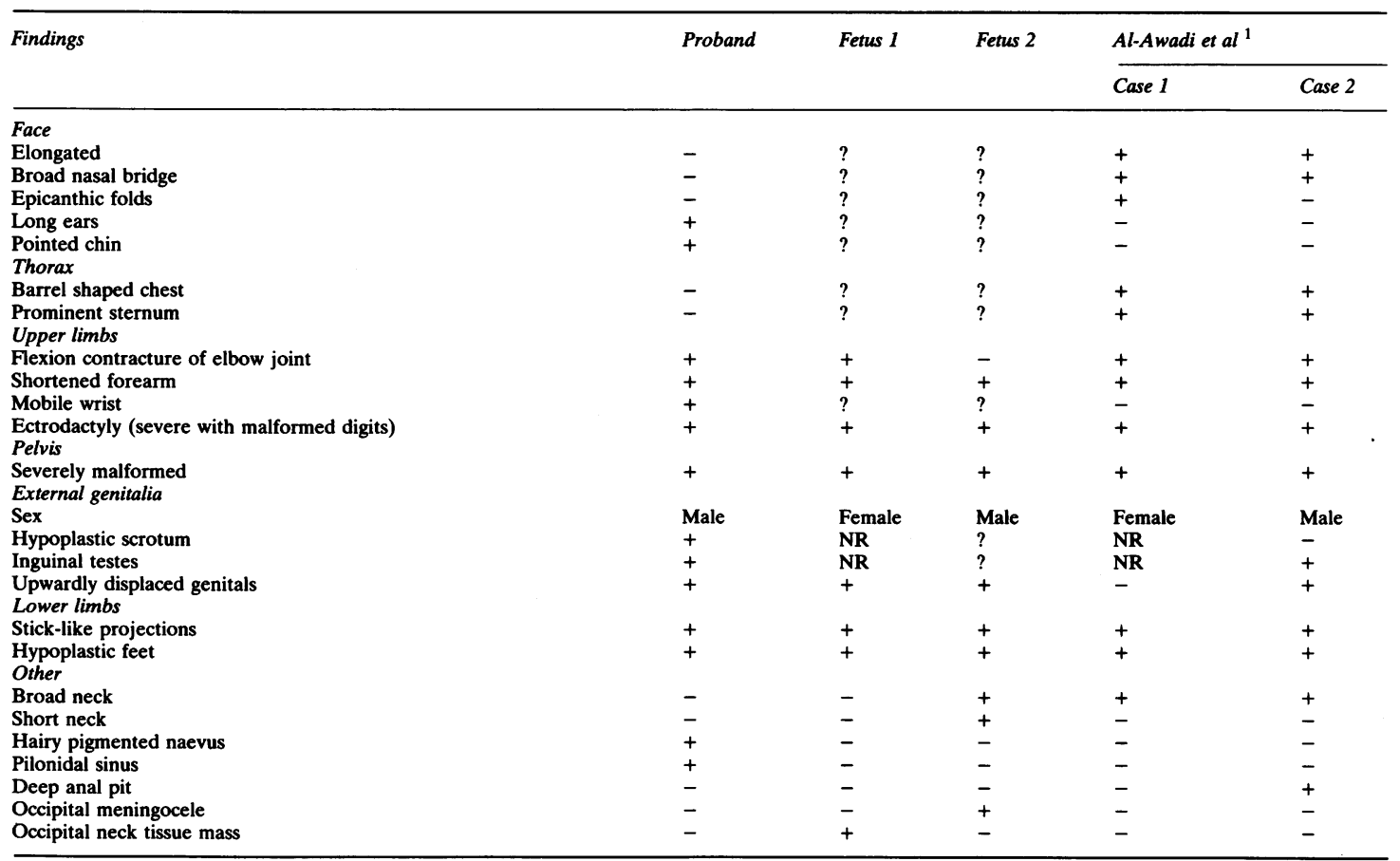

$+=$ present; $-=$ not present or not mentioned; ?=too early to know; NR=not relevant. 
TABLE 2 Radiographical findings in our affected family members compared with those cases reported by Al-Awadi et al. ${ }^{1}$

\begin{tabular}{|c|c|c|c|c|c|}
\hline \multirow[t]{2}{*}{ Findings } & \multirow[t]{2}{*}{ Proband } & \multirow[t]{2}{*}{ Fetus 1} & \multirow[t]{2}{*}{ Fetus 2} & \multicolumn{2}{|c|}{ Al-Awadi et al ${ }^{1}$} \\
\hline & & & & Case 1 & Case 2 \\
\hline \multicolumn{6}{|l|}{ Upper limbs } \\
\hline Shortened and bowed radii & + & $?$ & $?$ & + & + \\
\hline Aplasia of ulna & + & + & + & + & + \\
\hline Aplasia of carpal bones & + & + & + & - & - \\
\hline $\begin{array}{l}\text { Hypoplasia/aplasia of metacarpals and phalanges } \\
\text { Pelvis }\end{array}$ & + & + & + & + & + \\
\hline $\begin{array}{l}\text { Hypoplasia of pelvic bones } \\
\text { Lower limbs }\end{array}$ & + & $?$ & $?$ & + & + \\
\hline Short, bowed/separated hypoplastic femur & + & + & + & + & + \\
\hline Aplasia of fibula & + & + & + & + & + \\
\hline $\begin{array}{l}\text { Hypoplasia/aplasia of tarsals, metatarsals, and phalanges } \\
\text { Thorax }\end{array}$ & + & + & + & + & + \\
\hline Broad clavicles & + & + & + & - & - \\
\hline Broad ribs & + & + & + & - & - \\
\hline
\end{tabular}

$+=$ present; $-=$ not present or not mentioned; $?=$ too early to know.
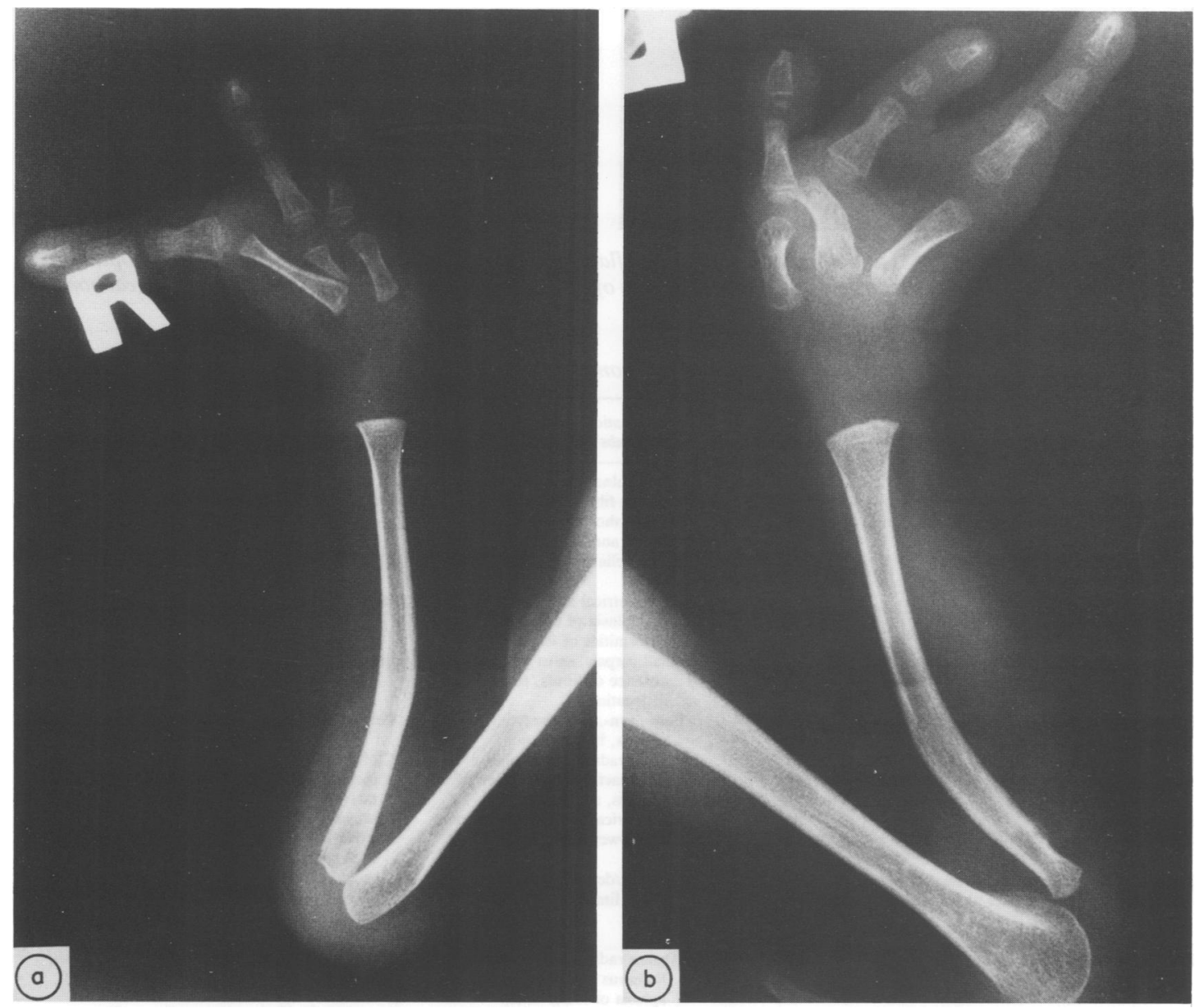

FIG $4 X$ ray of proband's upper limbs $(a, b)$ showing aplasia of ulna, carpal, and other digital bones. Note the bowed and relatively shortened radii. 
whorls, one each on digits I, II, and III. There were no transverse creases overlying the metacarpophalangeal joints; however, transverse creases were present on the distal interphalangeal joints of digits I and II of both hands. Digit III bilaterally had no transverse creases.

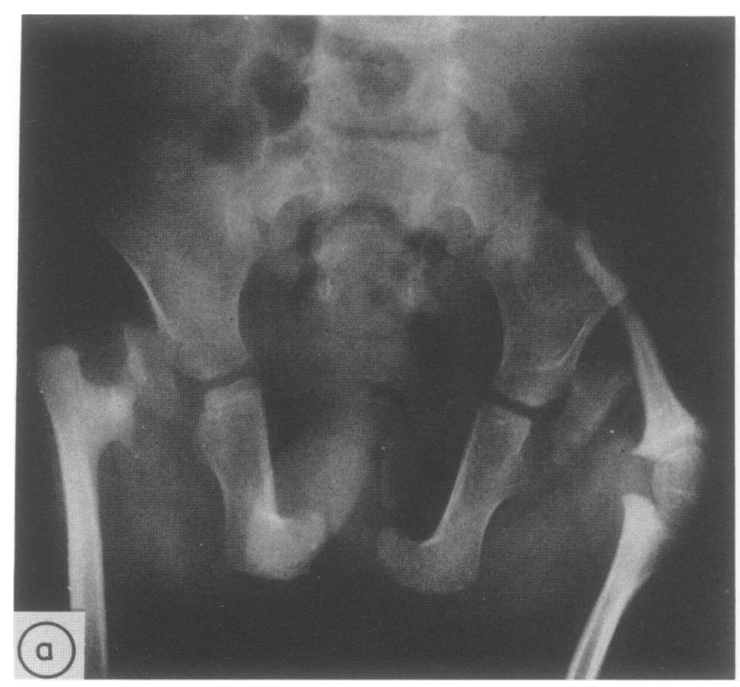

At present, the proband is able to use his upper limbs independently. He can grip between his two fingers, but has some difficulty with opposition of the thumb. Feeding himself is not a major problem. The lower limbs cannot be used for support or movement, but he ambulates by moving his trunk

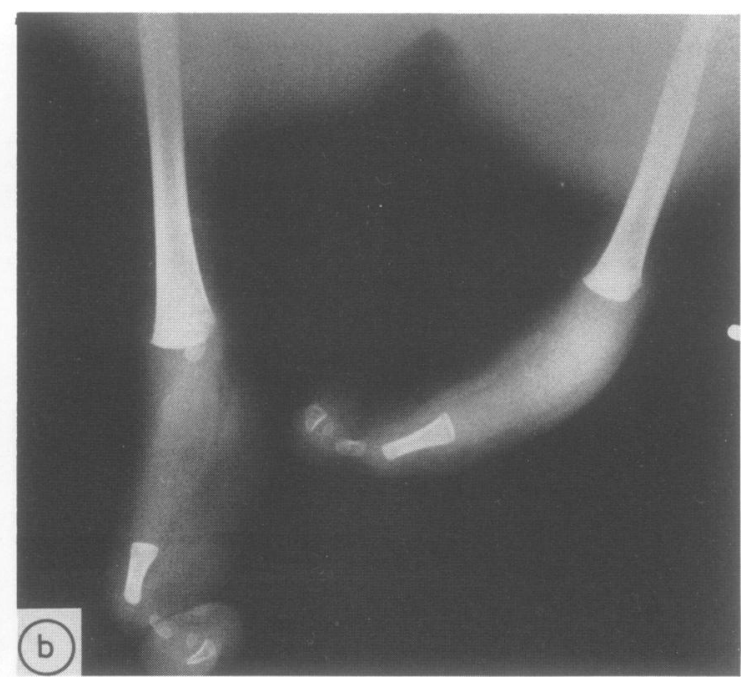

FIG $5 X$ ray of proband's pelvis and lower limbs. (a) Small flared iliac wings, absent right pubic bone, and hypoplastic distal femoral segment larger on the left. (b) Bilateral aplasia of fibula, with one tarsal, metatarsal, and phalangeal bone.

TABLE 3 Known or presumed genetic syndromes of autosomal recessive inheritance with major limb malformations.

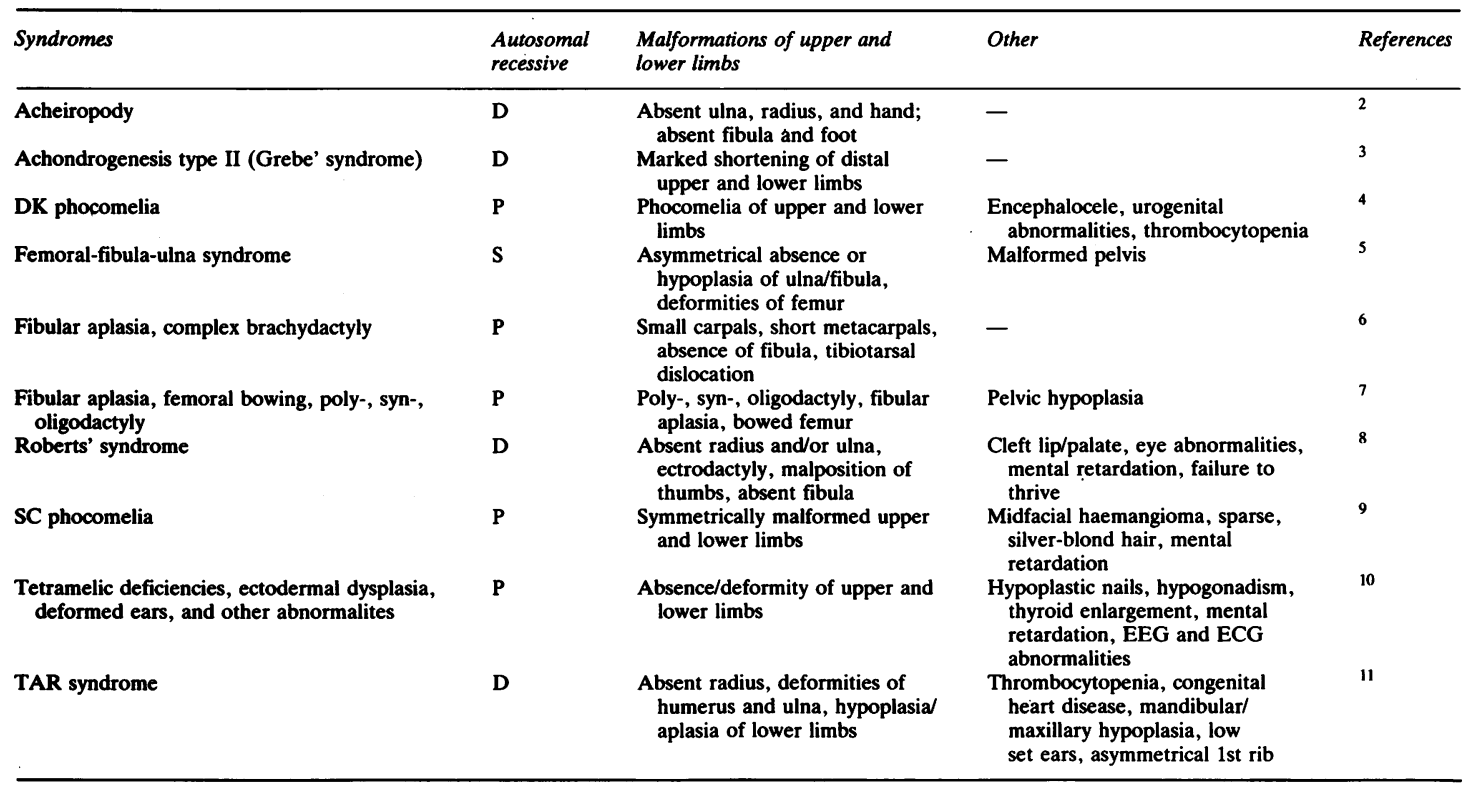

$\mathrm{D}=$ definitely autosomal recessive; $\mathrm{P}=$ presumed to be autosomal recessive; $\mathrm{S}=$ usually sporadic cases described. 
and pelvis by means of a swivel-bucket brace. At present, there are no plans for further orthopaedic intervention.

As mentioned previously, his intellectual development is considered to be normal and he attends the daily hospital kindergarten. It is hoped that next year he will go to a kindergarten outside the hospital in preparation for future schooling.
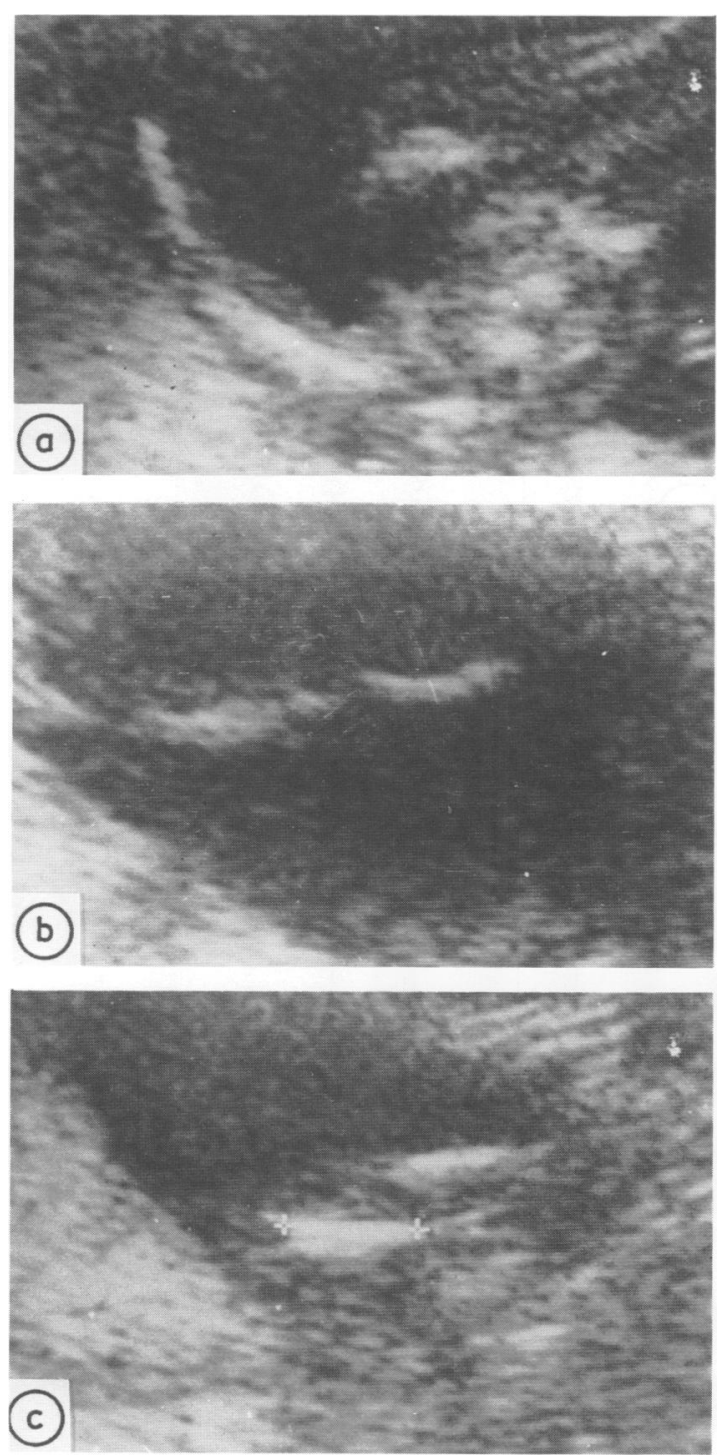

FIG 6 (a) Ultrasound at 14 weeks showing normal length humerus with short, single forearm bone; (b) short, single forearm bone ending in a hypoplastic hand; (c) two malformed and malpositioned bones of the lower limbs.

\section{Family history}

- The parents of the proband were double first cousins (fig 1) of Oriental Jewish ancestry, originating from the city of Mashad in Iran. The mother was 27 years old and the father 29 years at the birth of the proband. A healthy female child was born three years previously.

\section{Two other affected pregnancies}

Within a period of three years, the proband's mother became pregnant twice. Prenatal diagnosis using ultrasound showed that both of these pregnancies were affected with the same skeletal disorder as the proband had. A more detailed description of each of these pregnancies and the associated fetal malformations are given below.

The third pregnancy was uneventful until the 12th week when an ultrasound examination showed findings strongly suggestive of limb malformations. Two weeks later, ultrasonographic findings confirmed the presence of a normal length humerus with a short, single forearm bone ending in a malformed hypoplastic hand. There were abnormal lower limbs formed by one shortened, malformed bone that was thought to be an abnormal femur (fig 6). The pregnancy was terminated at the request of the parents. At necropsy, a female fetus showed severe upper and lower limb malformations similar to those noted in the proband. The right hand consisted of two abnormally shaped fingers and a hypoplastic thumb, while on the left hand there was also a hypoplastic thumb and a single malformed digit. Stick-like appendages extended from the pelvic region ending in poorly defined, hypoplastic feet. The external genitalia appeared hypoplastic. There was a large, soft mass extending from the occipital region of the head to the posterior neck (fig 7). The abnormal skeletal findings on $x$ ray examination are shown in fig 8 and listed in table 2.

The fourth pregnancy was uneventful until the 15th week when ultrasonography detected oligohydramnios and upper and lower limb malformations

TABLE 4 Characteristic skeletal involvement in the limb/ pelvis-hypoplasialaplasia syndrome*.

\begin{tabular}{lll}
\hline Upper limbs & Lower limbs & Pelvis \\
\hline Shortened, bowed radii & Hypoplasia of femur & $\begin{array}{c}\text { Hypoplastic } \\
\text { and malformed }\end{array}$ \\
$\begin{array}{l}\text { Aplasia of ulna } \\
\begin{array}{c}\text { Ectrodactyly (severe with } \\
\text { malformed digits) }\end{array}\end{array}$ & $\begin{array}{l}\text { Aplasia of fibula } \\
\text { Hypoplasia of feet }\end{array}$ & \\
\hline
\end{tabular}

*Involvement is bilateral and tends to be symmetrical. Above observations noted in our three reported cases and in the two cases reported by Al-Awadi et al. ${ }^{\prime}$ 

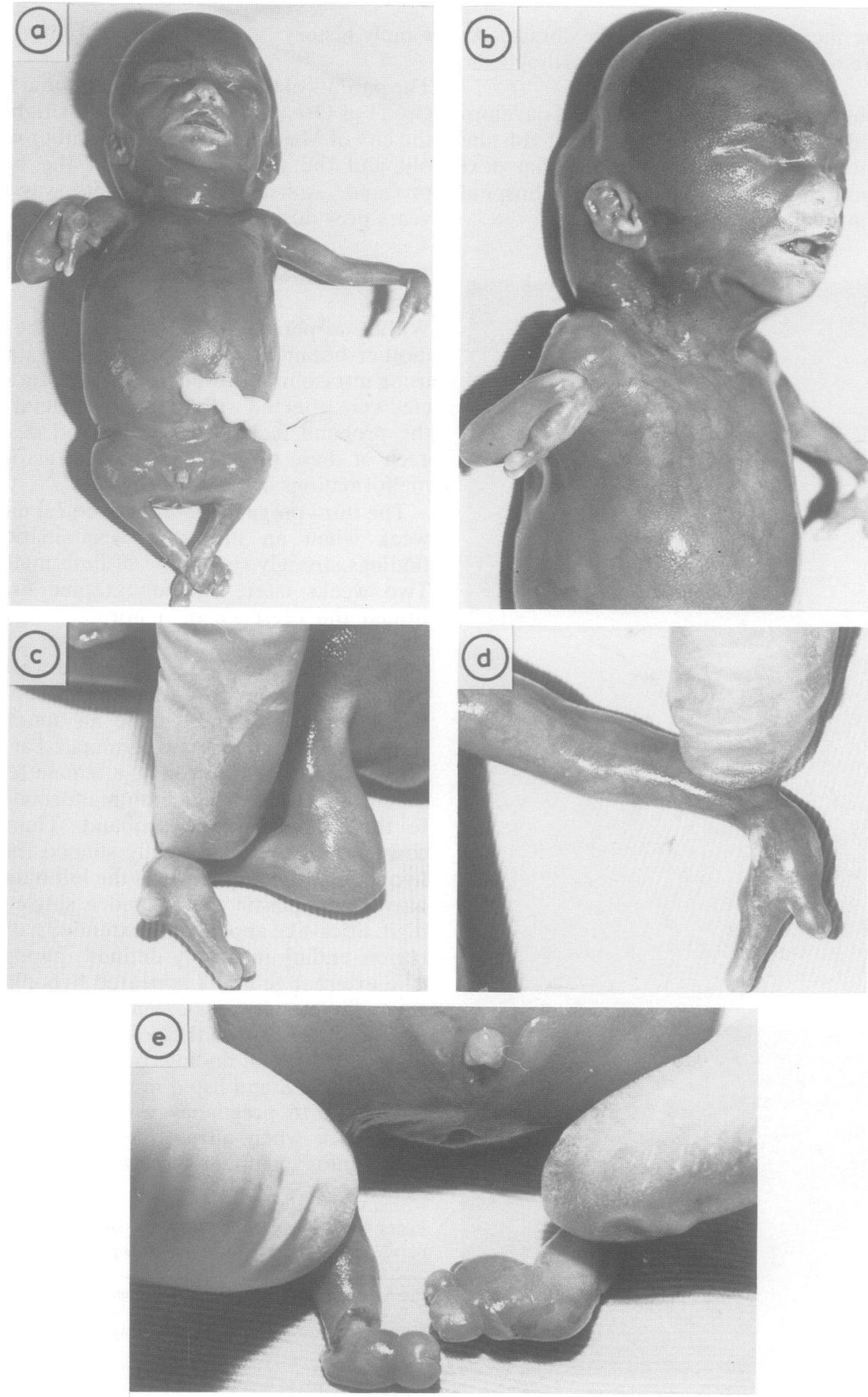

FIG 7 (a-d) Female fetus of 17 weeks with malformed upper extremities, contacture of right elbow, severe ectrodactyly of the hands, and an occipital mass extending to the posterior region of the neck. (e) Hypoplastic external genitalia and sticklike appendages extending from the pelvic region with poorly defined feet.
焉

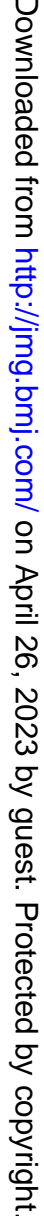



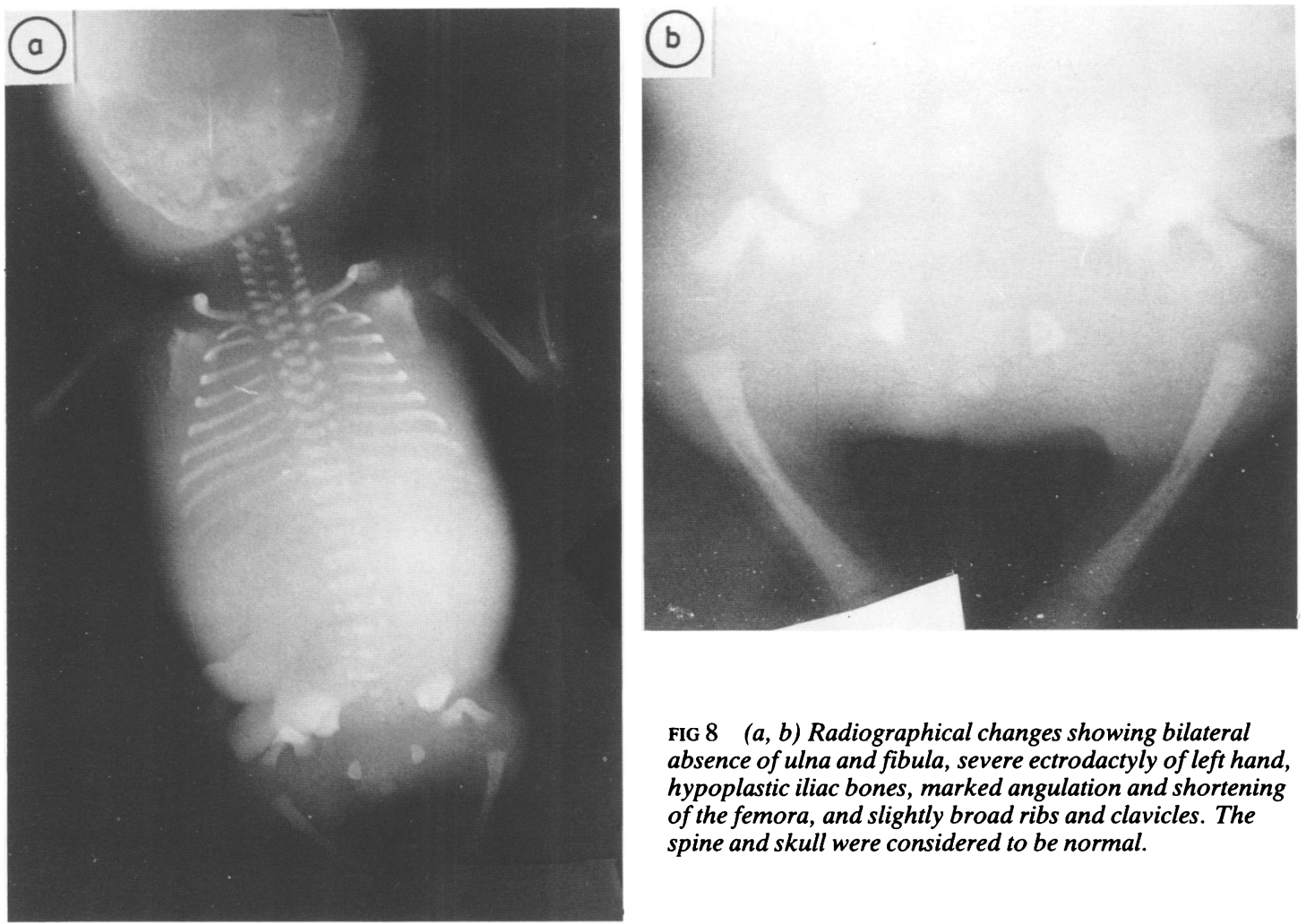

FIG 8 ( $a, b)$ Radiographical changes showing bilateral absence of ulna and fibula, severe ectrodactyly of left hand, hypoplastic iliac bones, marked angulation and shortening of the femora, and slightly broad ribs and clavicles. The spine and skull were considered to be normal.

similar to those noted in the previous pregnancy. This pregnancy was terminated in the 18 th week of gestation. At necropsy, a male fetus showed severe upper and lower limb malformations. The upper extremities were shortened and ended in a single malformed digit. The lower extremities were sticklike and folded posteriorly, ending in poorly defined, hypoplastic feet. The external genitalia appeared hypoplastic. In addition, the fetus had a short, broad neck and a occipital meningocele (fig 9). Necropsy findings of the brain confirmed the presence of the meningocele and also showed hypoplasia of the cerebellum. No other abnormalities of the internal organs were noted. The abnormal skeletal findings on $x$ ray examination are listed in table 2 .

\section{Discussion}

Table 3 lists the main autosomal recessive syndromes that involve major congenital malformations of the upper and lower limbs. The clinical findings in our three cases are unique and thus can be distinguished easily from those listed in table 3. In 1985, Al-Awadi et $a^{1}$ first described this condition which they called "the profound limb deficiency, thoracic dystrophy, unusual facies, and normal intelligence syndrome". The main characteristic findings (table 4) in this disorder, consisting of symmetrical hypoplasia/ aplasia of the upper and lower extremities and the pelvis, prompted us to rename this syndrome the limb/pelvis-hypoplasia/aplasia syndrome. We believe our terminology emphasises the major sites of involvement and, for us, the facial and thoracic findings do not seem to be outstanding features. Although intelligence was reported to be normal in the two patients of Al-Awadi et al ${ }^{1}$ and in our proband, one aborted fetus had a meningocele and hypoplastic changes in the cerebellum, so it may be too soon to state whether or not normal intelligence is always present in this syndrome. Similarly it is premature to state the degree and kinds of internal malformations (agenesis of a kidney in the proband and meningocele and hypoplasia of the cerebellum in one aborted fetus) that may be associated with 

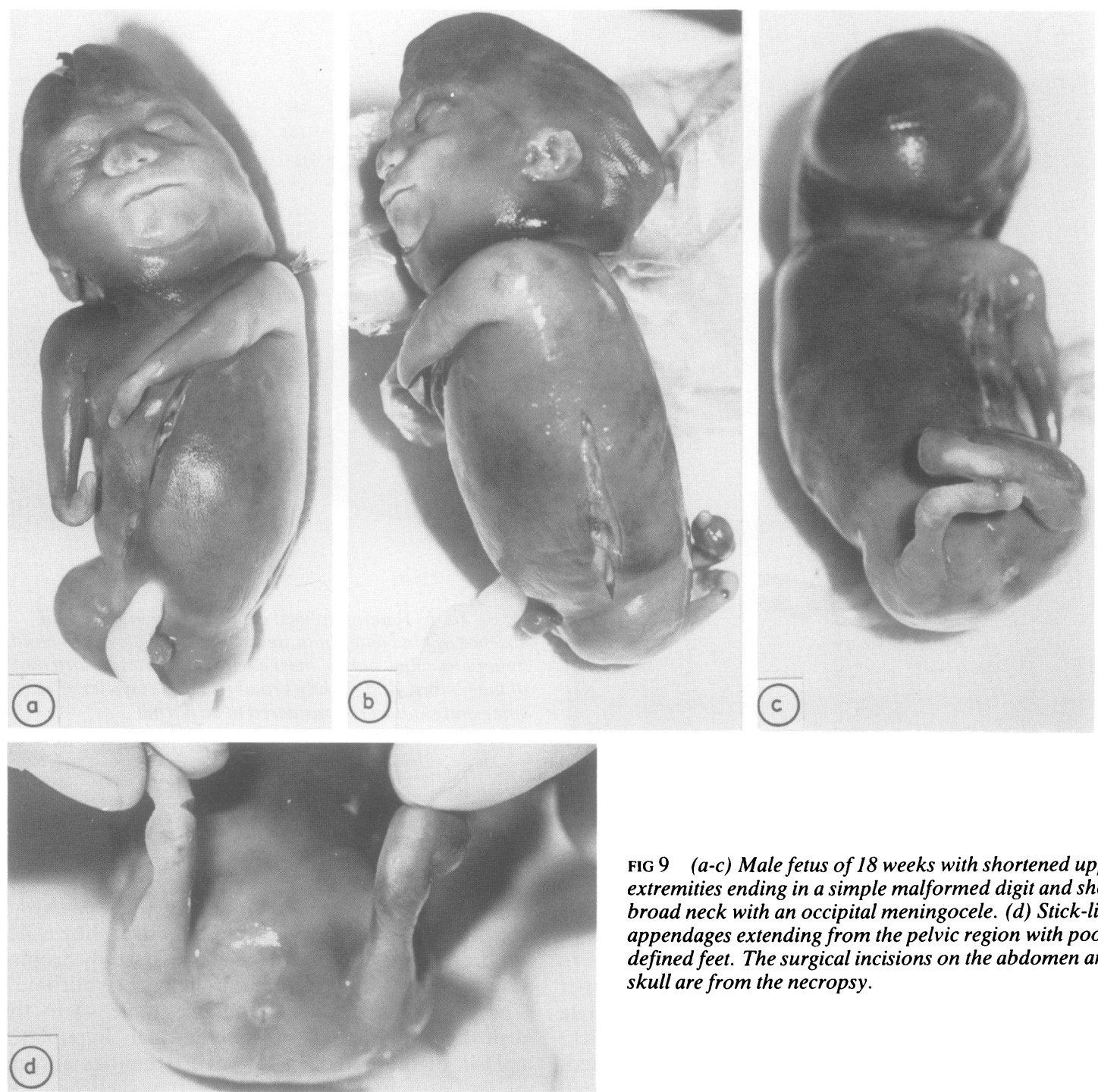

FIG 9 (a-c) Male fetus of 18 weeks with shortened uppe्छ extremities ending in a simple malformed digit and shor. broad neck with an occipital meningocele. (d) Stick-like appendages extending from the pelvic region with poorly defined feet. The surgical incisions on the abdomen and 3 skull are from the necropsy.

this syndrome. Dermatoglyphic findings were markedly abnormal as one would expect with the presence of severe ectrodactyly. ${ }^{12}$

The inheritance of this syndrome seems undoubtedly to be autosomal recessive. The gene must be quite rare as the parents were closely related first cousins in the family of $\mathrm{Al}$-Awadi et al ${ }^{1}$ and double first cousins in our family. Since the parents in both families are healthy and without physical findings, the heterozygous state cannot be detected clinically.

It is interesting to speculate whether or not this rare gene is confined to the Middle East gene pool.
The Moslem Arab family of Al-Awadi et al ${ }^{1}$ originated from the village of Silat Al-Hartheya on the west bank of the Jordan river, while our family has its origin in the Oriental Jewish community of Mashad in Iran.

At present, we have no knowledge regarding the basic defect or gene location of this disorder. Since the limb malformations are of such a major degree, they can easily be recognised early in the second trimester by means of ultrasound, thus making possible the prenatal diagnosis of this syndrome.

In summary, we have described a second affected 
family with the autosomal recessive disorder now referred to as the limb/pelvis-hypoplasia/aplasia syndrome. It is speculated that the gene for this rare skeletal dysplasia may be confined to the Middle East gene pool. The disorder has been shown to be diagnosable prenatally early in the second trimester in a pregnancy at risk using ultrasound examination.

The authors are indebted to Mrs Ruth Grossman and Sam Meiselman for their kind efforts with the word processor and Mrs Irit Behor for her photographic assistance. This work was supported in part by grants to RMG from the National Foundation for Jewish Genetic Diseases and LA-CO Industries Inc in the USA and the Henry Goldberg Memorial Fund in Israel.

\section{References}

1 Al-Awadi SA, Teebi AS, Farag TI, Naguib KM, El-Khalifa MY. Profound limb deficiency, thoracic dystrophy, unusual facies, and normal intelligence: a new syndrome. $J$ Med Genet 1985;22:36-8.

2 Freire-Maia A. The extraordinary handless and footless families of Brazil-50 years of acheiropodia. Am J Med Genet 1981;9: 31-42.

${ }^{3}$ Kumar D, Curtis D, Blank CE. Grebe chondrodysplasia and brachydactyly in a family. Clin Genet 1984;25:68-72.

4 Cherstvoy E, Lazjuk G, Lurie L, et al. Syndrome of multiple congenital malformations including phocomelia, thrombocytopenia, encephalocele and urogenital abnormalities. Lancet 1980;ii:485.

5 Aitken GT. Proximal femoral focal deficiency-definition, classification, and management. In: Aitken GT, ed. Proximal femoral focal deficiency, a congenital anomaly. Washington DC: National Academy of Sciences, 1969: 1-22.

6 McKusick VA. Mendelian inheritance in man. 7th ed. Baltimore: Johns Hopkins University Press, 1986:970.

7 Furhmann W, Furhmann-Reiges A, de Sousa F. Poly-, syn-, and oligodactyly, aplasia or hypoplasia of fibula, hypoplasia of pelvis and bowing of femora in three sibs: a new autosomal recessive syndrome. Eur J Pediatr 1980;133:123-9.

8 Herrmann J, Opitz JM. The SC phocomelia and the Roberts syndrome: nosologic aspects. Eur J Pediatr 1977;125:117-34.

9 Hall BD, Greenberg MH. Hypomelia-hypotrichosis-facial hemangioma syndrome (pseudothalidomide, SC syndrome, SC phocomelia syndrome). Am J Dis Child 1972;123:602-4.

10 Freire-Maia N. A newly recognised genetic syndrome of tetramelic deficiencies, ectodermal dysplasia, deformed ears and other abnormalities. Am J Hum Genet 1970;22:371-7.

11 Anyane-Yeboa K, Jaramillo S, Nagel C, et al. Brief clinical report. Tetraphocomelia in the syndrome of thrombocytopenia with absent radii (TAR syndrome). Am J Med Genet 1985;20: 571-6.

12 MacKenzie HJ, Penrose LS. Two pedigrees of ectrodactyly. Ann Eugen 1951;16:88-96.

Correspondence and requests for reprints to Professor R M Goodman, Department of Medical Genetics, Sheba Medical Center, Tel Hashomer 52621, Israel. 